\title{
Estrutura e valor nutritivo de pastos de capins Tanzânia e Marandu aos 22 e 36 dias de rebrota para ovinos ${ }^{1}$
}

\author{
Structure and nutritional value of pasture grasses of Tanzania and Marandu at 22 and \\ 36 days of regrowth for sheep
}

\section{SANTOS, Maurílio Souza dos ${ }^{2 *}$; OLIVEIRA, Maria Elizabete de ${ }^{3}$; RODRIGUES, Marcônio Martins²; VELOSO FILHO, Edvar dos Santos²; ARAUJO NETO, José Cardoso de ${ }^{2}$}

${ }^{1}$ Parte da dissertação de mestrado do primeiro autor.

${ }^{2}$ Universidade Federal do Piauí, Centro de Ciências Agrárias, Programa de Pós-Graduação em Ciência Animal, Teresina, Piauí, Brasil.

${ }^{3}$ Universidade Federal do Piauí, Centro de Ciências Agrárias, Departamento de Zootecnia, Teresina, Piauí, Brasil.

*Endereço para correspondência: maurílio.vet@hotmail.com

\section{RESUMO}

Esta pesquisa foi desenvolvida durante a estação chuvosa no setor de caprinos do Departamento de Zootecnia da Universidade Federal do Piauí com o objetivo de avaliar a estrutura do pasto e o valor nutritivo para ovinos de pastos dos capins Marandu e Tanzânia aos 22 e 36 dias de crescimento. Foram avaliadas a massa de forragem, altura, porcentagem de folhas, de colmos e de material morto do pasto, a composição químico-bromatológica, digestibilidade e o consumo de forragem por ovinos. A ocorrência de veranicos durante o período de rebrota de 36 dias resultou no menor crescimento das plantas, sem que houvesse diferença entre as idades para a massa de forragem, altura do pasto e porcentagem de folhas. $\mathrm{O}$ prolongamento do período de crescimento resultou em aumento na proporção de material morto no pasto, queda do valor nutritivo da forragem, com redução do teor de proteína bruta e da digestibilidade e elevação dos teores de fibras em detergente neutro e acido. O consumo de forragem foi equivalente entre as gramíneas, sendo que aos 36 dias de rebrota o consumo de nutrientes seria suficiente apenas para a mantença, e o prolongamento do período de rebrota de 22 para 36 dias leva à redução no consumo de forragem por ovinos devido à queda na qualidade da forragem, tanto do seu valor nutritivo como da estrutura do dossel.

Palavras-chave: consumo a pasto, cordeiro, digestibilidade da matéria seca,

\section{SUMMARY}

This research was conducted during the rainy season in the goats sector of the Department of Animal Science of Federal University of Piauí with the objective to evaluate the morphology and nutritive value of sward for sheep in pastures of Marandu and Tanzania at 22 and 36 days of growth. It were evaluated the herbage mass, sward height, percentage of leaf, stem and dead material, the chemical composition, digestibility and forage intake by sheep. The occurrence of dry spells during the regrowth period of 36 days, resulted in lower growth of plants, with no difference between ages for herbage mass, sward height and percentage of leaves. The extension of the growing season resulted in increased proportion of dead material in pasture, decrease in nutritional value of forage, with a reduction in crude protein content and digestibility and increased in neutral detergent fiber and acid detergent fiber. Forage intake was similar among the grasses, whereas at 36 days of regrowth nutrient intake would be sufficient only for maintenance and the extension of regrowth period of 22 to 36 days leads to a reduction in forage intake by sheep due to a drop in forage quality, much of its nutritional value as the sward structure.

Keywords: dry matter digestibility, itake forage, lamb 


\section{INTRODUÇ̃̃̃O}

O uso de pastos cultivados é uma estratégia para a alimentação de ovinos, pois contribui para a estabilidade de produção e redução de custos financeiros (SANTELLO et al., 2006). O uso desses pastos é uma alternativa ao confinamento e ao uso de pastagens nativas devido à produtividade e valor nutritivo das gramíneas forrageiras, notadamente dos capins de origem africana (EUCLIDES et al., 2007). Essas gramíneas pertencem ao grupo de plantas $\mathrm{C} 4$ que coevoluiram com grandes herbívoros (BOUCHENAKKHELLAD et al., 2009) o que resultou em alta capacidade de produção de massa e de resiliência ao pastejo da maioria das espécies das poáceaes.

No entanto, para alcançar elevados níveis de produção animal, torna-se necessário conhecer não apenas as características físicas, e estruturais das espécies forrageiras, a quantidade de forragem oferecida aos animais e a sua composição química, mas, também a quantidade de forragem a ser consumida pelo animal (BRÂNCIO et al., 2003).

Para animais em pastejo o consumo de forragem é determinante do desempenho, e influenciado por fatores associados ao animal, ao pasto e ao ambiente (CARVALHO et al., 2007; NRC, 2007).

Com relação ao pasto, tanto as características estruturais quanto o seu valor nutritivo podem variar em função do período de crescimento da planta (TAMASSIA et al., 2001; PACIULLO et al., 2001), o que implica em variações no consumo e desempenho dos animais. Nos pastos mais jovens ocorre maior participação de folhas, e como resultado, maior digestibilidade da matéria seca (SUN et al., 2010). Com o aumento da idade de rebrotação, observa-se maior participação de colmo e material senescente, e assim, uma redução na qualidade da forragem no pasto (JANUSCKIEWICZ et al., 2010). A magnitude dessas variações está associada a elementos climáticos (FAGUNDES et al., 2006), e deste modo, variam entre diferentes ambientes.

Ao se ter em vista a escassez de informações relacionadas ao consumo por ovinos em pastejo na região MeioNorte, esta pesquisa foi realizada com o objetivo de avaliar a estrutura do pasto, a composição química e o consumo de forragem por ovinos em pastos dos capins Marandu e Tanzânia aos 22 e 36 dias de crescimento durante o período chuvoso.

\section{MATERIAL E MÉTODOS}

Esta pesquisa foi realizada durante a estação chuvosa, no Campus da Universidade Federal do Piauí, na cidade de Teresina, PI (latitude $05^{\circ} 05^{\prime} 21$ 's, longitude $42^{\circ} 48^{\prime} 07^{\prime \prime}$ W). O clima é classificado como subúmido seco, megatérmico com excedente hídrico moderado no verão. A precipitação pluviométrica anual média é $1.200 \mathrm{~mm}$ e a temperatura anual média $28^{\circ} \mathrm{C}$. Conforme o sistema Köppen, a região é classificada como Aw-Tropical chuvoso de Savana, com inverno seco (junho a novembro) e verão chuvoso (dezembro a maio), e a maior precipitação pluviométrica se concentra nos meses de janeiro a abril. A pluviosidade acumulada foi $594 \mathrm{~mm}$ distribuída durante o período experimental, que foi de 90 dias, nos meses de fevereiro a maio conforme apresentado na Figura 1. O solo da área experimental foi classificado como Latossolo Vermelho-Amarelo, com as seguintes características químicas: $\mathrm{pH}$ em água 5,3; Ca 1,1; Mg 0,3; K 0,1 e Al $0,1 \mathrm{cmol} / \mathrm{dm}^{3} ; \mathrm{P}$ disponível $3 \mathrm{mg} / \mathrm{dm}^{3}$; e, 
matéria orgânica $7,7 \mathrm{mg} / \mathrm{kg}$. Os pastos foram estabelecidos no ano de 2000 , e antes do início do experimento foi realizado um corte de uniformização a $10 \mathrm{~cm}$ do solo com roçadeira costal, seguido análise de solo realizada na área, procedeu-se adubação com $110 \mathrm{~kg} / \mathrm{ha}$ de ureia, $176,5 \mathrm{~kg} / \mathrm{ha}$ de superfosfato triplo e $100 \mathrm{~kg} / \mathrm{ha}$ de cloreto de potássio.

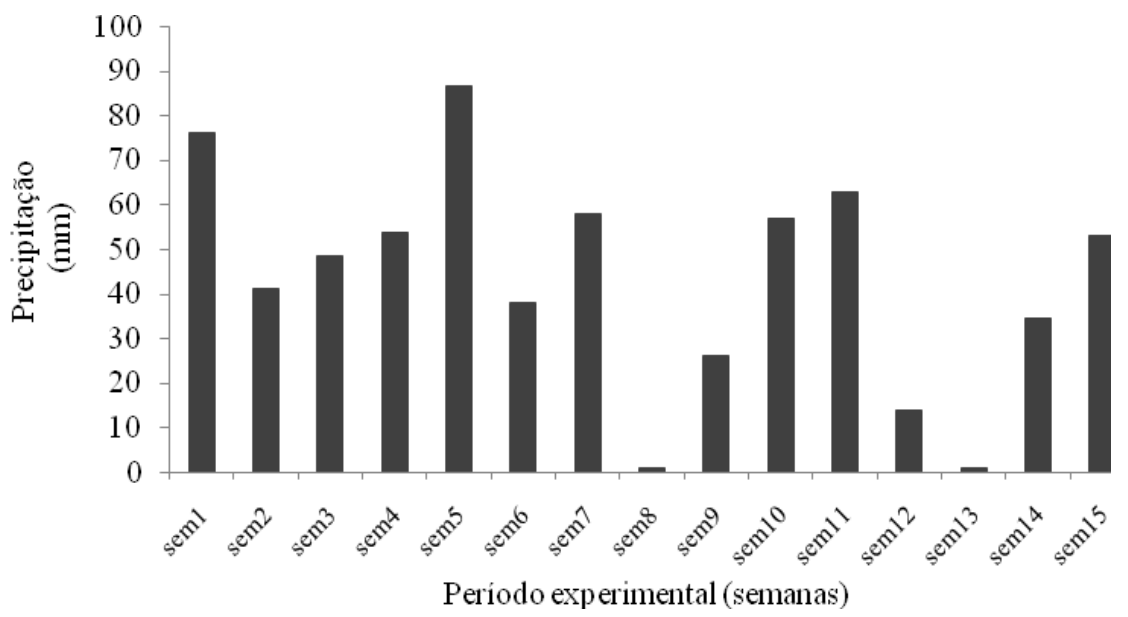

Figura 1. Precipitação pluviométrica nos meses de fevereiro a maio, período chuvoso, Teresina, PI. Fonte: Estação Meteorológica da Embrapa Meio-Norte

A área experimental, com $0,66 \mathrm{ha}$ e topografia plana foi subdividida em duas subáreas com 0,33 ha cada, uma cultivada com Brachiaria brizantha cv. Marandu, e outra com Panicum maximum cv. Tanzânia. Cada subárea foi dividida em 10 piquetes com área útil de $333 \mathrm{~m}^{2}$. Foram sorteados cinco piquetes para o período de rebrota de 22 dias e outros cinco para o período de rebrota de 36 dias em cada subárea, o que totalizou 20 piquetes (parcelas).

Desse modo, os tratamentos foram formados pelos fatores gramíneas (Marandu e Tanzânia) e idades de rebrota (22 e 36 dias), com cinco repetições (piquetes).

As subáreas foram submetidas ao pastejo sob lotação rotativa, com quatro dias de ocupação e período de descanso de 22 e 36 dias, de acordo com o tratamento empregado. A área experimental foi pastejada por ovelhas da raça Santa Inês com peso corporal médio de $30 \pm 2,9 \mathrm{~kg}$, das quais eram seis animais experimentais por tratamento mais animais reguladores para controlar a oferta de forragem, de modo a se obter uma oferta de forragem correspondente a $8 \%$ do peso corporal.

A altura do dossel forrageiro foi medida com uso de régua graduada em nove pontos por piquete (repetição) em um total de 45 medições por tratamento. Para tal, foi marcada a distância do solo em relação à curvatura da folha mais alta sem modificar a estrutura, ou seja, sem esticar ou comprimir as plantas.

Para avaliar a massa de forragem (MF), a composição morfológica e o valor nutritivo da forragem antes da entrada dos animais em cada piquete, foi realizada a coleta de três amostras de forragem com quadro com dimensões 
de $1,0 \times 0,5 \mathrm{~m}$ cortadas a uma altura de $10 \mathrm{~cm}$ do solo. A média destas três amostras foi considerada uma repetição. Após coleta e identificação das amostras, as mesmas foram levadas ao Laboratório de Nutrição Animal do Departamento de Zootecnia do CCA/UFPI para serem pesadas, separadas e para determinação do valor nutritivo.

Após a pesagem foram retiradas três subamostras de forragem, uma para determinação do valor nutritivo da forragem, outra para separação das porções lâminas foliares e bainhas + colmos, e uma terceira subamostra para separação do material verde do material senescente. As subamostras foram acondicionadas em sacos de papel, pesadas e submetidas à pré-secagem a $65^{\circ} \mathrm{C}$ em estufa de circulação forçada de ar por 72 horas para determinação da matéria pré-seca, e em seguida foram moídas em moinho tipo Willey com peneira de $1,0 \mathrm{~mm}$ e submetidas a determinação dos teores de matéria seca (MS) e proteína bruta (PB), segundo as metodologias descritas por Silva \& Queiroz (2002). Os teores de fibra em detergente neutro (FDN) e fibra em detergente ácido (FDA) foram obtidos pelo método de Van Soest (1991), descrito por Souza et al. (1999), e a digestibilidade in vitro da matéria seca (DIVMS) e da matéria orgânica (DIVMO) foram determinadas pela técnica de Tilley \& Terry (1963).

A estimativa do consumo diário de MS foi obtida pela técnica indireta, pela razão da produção fecal total diária (PFT) e a indigestibilidade da MS ingerida pelo animal conforme a equação abaixo adaptada de Detmann et al. (2001).

$$
\text { Consumo }(\mathrm{g} \text { de } \mathrm{MS} / \mathrm{dia})=\frac{\mathrm{PFT}}{1-\mathrm{DIVMS}}
$$

Em que:

PFT = Produção fecal total de cada ovino, em g de MS fecal/dia;

DIVMS = Digestibilidade in vitro da forragem ingerida pelo animal.

A produção fecal diária foi estimada com a utilização do óxido de cromo $\left(\mathrm{Cr}_{2} \mathrm{O}_{3}\right)$ como marcador externo, administrado conforme recomendado por Detmann et al. (2001). Seis animais em cada tratamento receberam, durante 20 dias, às $07 \mathrm{hs}$ e $17 \mathrm{hs}, 1,0 \mathrm{~g}$ de $\mathrm{Cr}_{2} \mathrm{O}_{3}$, embalado em cápsulas absorvíveis e introduzido no esôfago. Os primeiros 15 dias da administração do $\mathrm{Cr}_{2} \mathrm{O}_{3}$ destinaram-se à adaptação dos animais e para se atingir o estado de equilíbrio do fluxo de $\mathrm{Cr}_{2} \mathrm{O}_{3}$ no trato gastrintestinal.

Nos últimos cinco dias, quando do fornecimento do $\mathrm{Cr}_{2} \mathrm{O}_{3}$, foram realizadas coletas de fezes diretamente do reto dos animais, seguindo o mesmo horário de administração do $\mathrm{Cr}_{2} \mathrm{O}_{3}$ (DETMANN et al., 2001). As amostras de fezes coletadas foram conservadas em freezer $\left(-5\right.$ a $\left.-10^{\circ} \mathrm{C}\right)$ até o processamento. Para determinação da concentração de $\mathrm{Cr}_{2} \mathrm{O}_{3}$ nas fezes foi formada uma amostra composta dos cinco dias de coleta por animal. As amostras foram secas em estufa com circulação forçada de ar a $50{ }^{\circ} \mathrm{C}$, moídas e acondicionadas em sacos plásticos. A concentração de cromo foi estimada mediante utilização de um espectrofotômetro de absorção atômica, conforme metodologia proposta por Williams et al. (1962), descrita por Silva \& Queiroz (2002), e foi determinada a produção fecal total, pela equação abaixo proposta por Berchielli et al. (2005).

Para se obter a DIVMS, DIVMO e PB da forragem ingerida foram coletadas amostras de forragem manualmente, simulando-se o pastejo pelos animais no mesmo período da coleta de fezes. 
Rev. Bras. Saúde Prod. Anim., Salvador, v.13, n.1, p.35-46 jan/mar, 2012 http://www.rbspa.ufba.br ISSN 15199940

$$
\text { Produção fecal total }(\mathrm{g} \mathrm{MS} / \text { dia })=\frac{\text { Quantidade de } \mathrm{Cr}_{2} \mathrm{O}_{3}(\mathrm{~g})}{\text { Concentração de } \mathrm{Cr}_{2} \mathrm{O}_{3} \text { na MS fecal }(\mathrm{g} / \mathrm{gMS})}
$$

O consumo de PB e NDT foram estimados a partir das informações de consumo de MS, composição bromatológica e DIVMO da forragem coletada simulando-se o pastejo.

O NDT da forragem foi estimado a partir da DIVMO conforme equação proposta por Capelle et al. (2001).

$\%$ NDT $=-2,49+1,0167 \times$ DIVMO

Em que:

$\%$ NDT $=$ Porcentagem de NDT presente na forragem;

DIVMO $=$ Digestibilidade in vitro da matéria orgânica da forragem

Os consumos de NDT e PB (g/dia) foram obtidos por multiplicação do consumo de MS (g/dia) pela porcentagem de NDT e $\mathrm{PB}$, respectivamente, presente na forragem ingerida.

$\mathrm{O}$ delineamento experimental empregado foi inteiramente casualizado em esquema fatorial $2 \times 2$, com duas idades de rebrota (22 e 36 dias) e duas gramíneas (capim-Tanzânia e capim-Marandu) com cinco repetições (piquetes) para avaliação da massa de forragem, estrutura do pasto, composição bromatológica e digestibilidade da forragem, e seis repetições (animais) para avaliação do consumo. Para comparação de médias foi utilizado o teste de Duncan e adotado o nível de significância de 5\%. A análise estatística foi realizada mediante utilização do logiciário estatístico SAS (SAS INSTITUTE, 2004).

\section{RESULTADOS E DISCUSSÃO}

Não foi observada interação entre os fatores gramíneas e idades de rebrota para nenhuma das variáveis estruturais do pasto $(\mathrm{P}>0,05)$. A altura do dossel forrageiro e massa de forragem (Tabela 1) não diferiram entre as duas idades de rebrota $(\mathrm{P}>0,05)$ como era esperado, com base em diversos trabalhos que avaliaram intervalos de rebrota similares (OLIVEIRA et al, 2005; CÂNDIDO et al, 2006; ARAÚJO et al, 2008 ). Este comportamento dos capins pode estar associado à distribuição de chuvas (Figura 1), notadamente na segunda idade de rebrota. A distribuição das chuvas durante o período de rebrota 22 dias $\left(1^{\mathrm{a}}\right.$ a $7^{\mathrm{a}}$ semana de experimento) foi mais uniforme, com pluviosidade acumulada de $300 \mathrm{~mm}$, e durante o período de rebrota 36 dias $\left(8^{\mathrm{a}}\right.$ a $15^{\mathrm{a}}$ semana de experimento), apesar da pluviosidade acumulada de $250 \mathrm{~mm}$, houve irregularidade na distribuição das chuvas com a ocorrência de veranicos, o que prejudicou o crescimento das plantas.

Foi observada maior altura do dossel forrageiro $(\mathrm{P}<0,05)$ para o capimTanzânia nas duas idades de rebrota (Tabela 1). Estes valores estão próximos aos observados por Brâncio et al. (2003) nas regiões Sudeste e Centro-Oeste para os capins Tanzânia e Marandu aos 35 dias de crescimento.

Para a porcentagem de folhas presentes no pasto não foi observada diferença estatística entre os capins e entre as idades de rebrota de 22 e 36 dias $(\mathrm{P}>0,05)$. O prolongamento da idade de rebrota de 22 para 36 dias resultou em aumento $(\mathrm{P}<0,05)$ na participação do material morto nas duas gramíneas (Tabela 1), o que pode ser associado à má distribuição das chuvas durante a idade de rebrota de 36 dias. Fagundes et al. (2006) afirmaram que a quantidade de material morto presente no pasto pode variar em função das condições climáticas. 
Rev. Bras. Saúde Prod. Anim., Salvador, v.13, n.1, p.35-46 jan/mar, 2012 http://www.rbspa.ufba.br ISSN 15199940

Tabela 1. Médias e erros-padrão da altura do pasto $(\mathrm{cm})$, massa de forragem ( $\mathrm{kg} \mathrm{MS} / \mathrm{ha}$ ), porcentagem de folhas e material morto dos pastos de capimTanzânia e capim-Marandu aos 22 e 36 dias de rebrota

\begin{tabular}{|c|c|c|c|c|}
\hline \multirow{2}{*}{ Capim } & \multicolumn{2}{|c|}{ Idade de rebrota } & \multirow{2}{*}{ Média } & \multirow{2}{*}{$\mathrm{CV}^{*}(\%)$} \\
\hline & 22 dias & 36 dias & & \\
\hline \multicolumn{5}{|c|}{ Altura do pasto $(\mathrm{cm})$} \\
\hline Tanzânia & $87,20 \pm 8,52$ & $86,78 \pm 12,87$ & $89,99^{\mathrm{a}}$ & \multirow{2}{*}{16,30} \\
\hline Marandu & $56,33 \pm 2,17$ & $56,26 \pm 8,88$ & $56,29^{\mathrm{b}}$ & \\
\hline Média & 71,76 & 71,52 & - & - \\
\hline \multicolumn{5}{|c|}{ Massa de forragem (kg MS/ha) } \\
\hline Tanzânia & $3.288,00 \pm 617,20$ & $3.360,4 \pm 1.003,59$ & $3.324,20$ & \multirow{2}{*}{23,13} \\
\hline Marandu & $2.733,60 \pm 540,16$ & $3.346,72 \pm 698,06$ & $3.040,20$ & \\
\hline Média & $3.010,80$ & $3.353,60$ & - & - \\
\hline \multicolumn{5}{|c|}{ Porcentagem de folha } \\
\hline Tanzânia & $59,80 \pm 9,08$ & $68,24 \pm 9,68$ & 64,02 & \multirow{2}{*}{14,52} \\
\hline Marandu & $68,17 \pm 8,60$ & $63,93 \pm 10,32$ & 66,05 & \\
\hline Média & 63,98 & 66,09 & - & - \\
\hline \multicolumn{5}{|c|}{ Porcentagem de material morto } \\
\hline Tanzânia & $20,15 \pm 9,03$ & $27,90 \pm 16,99$ & $24,02^{\mathrm{a}}$ & \multirow{2}{*}{61,83} \\
\hline Marandu & $4,66 \pm 1,06$ & $18,15 \pm 10,42$ & $11,40^{\mathrm{b}}$ & \\
\hline Média & $12,40^{\mathrm{B}}$ & $23,03^{\mathrm{A}}$ & - & - \\
\hline
\end{tabular}

Médias seguidas pela mesma letra minúscula nas linhas e maiúscula nas colunas não diferem entre si pelo Teste de Duncan a 5\%.

*Coeficiente de variação.

O valor do coeficiente de variação para a porcentagem de material morto foi elevado nesta pesquisa, assim como observado por outros autores (JANUSCKIEWICZ et al., 2010; BARBERO et al., 2009). Isto ocorre devido à subjetividade da avaliação desta variável, pois se considera como morto o perfilho com mais de $50 \%$ de senescência. Entretanto, observa-se que embora o coeficiente de variação tenha sido alto foi notada diferença estatística para a porcentagem de material morto tanto entre as gramíneas como entre as idades de rebrota $(\mathrm{P}<0,05)$.

Nas duas idades de rebrota, o capim-Tanzânia apresentou maior porcentagem de material morto que o capim-Marandu $(\mathrm{P}<0,05)$, o que pode ser atribuído ao porte mais elevado do capim-Tanzânia, que levou ao sombreamento das folhas mais baixas, e isto acelerou o processo de senescência destas. Situação semelhante foi descrita por Cândido et al. (2005). Elevada quantidade de material senescente no capim-Tanzânia também foi observada por Cecato et al. (2001), o que, segundo esses autores está associada a uma elevada perda de forragem.

Quanto ao valor nutritivo da forragem não foi observada interação significativa $(\mathrm{P}>0,05)$ entre os fatores capins e idades de rebrota para o teor de PB (Tabela 2), e o capim-Tanzânia apresentou maior teor de $\mathrm{PB}$ que o capim-Marandu. $\mathrm{O}$ prolongamento do período de rebrota resultou em redução no teor de $\mathrm{PB}$ dos dois capins $(\mathrm{P}<0,05)$. Chambela Neto et al. (2008) registraram teor de PB maior para estas duas gramíneas, $13,8 \%$ e $12,6 \%$ para os capins Tanzânia e 
Rev. Bras. Saúde Prod. Anim., Salvador, v.13, n.1, p.35-46 jan/mar, 2012 http://www.rbspa.ufba.br ISSN 15199940

Marandu respectivamente. A redução no teor de PB com o prolongamento do período de crescimento tem sido comprovada por diversos autores em região subúmida (ARAUJO et al., 2008;
OLIVEIRA et al., 2005) e, nesta pesquisa, deveu-se à elevação na quantidade de material senescente presente no pasto com maior idade de rebrota (Tabela 1).

Tabela 2. Médias e erros-padrão do teor de proteína bruta (PB), fibra em detergente neutro (FDN), fibra em detergente ácido (FDA), Digestibilidade in vitro da matéria seca (DIVMS) e da matéria orgânica (DIVMO) dos capins Tanzânia e Marandu aos 22 e 36 dias de rebrota

\begin{tabular}{|c|c|c|c|c|}
\hline \multirow{2}{*}{ Capim } & \multicolumn{2}{|c|}{ Idade de rebrota } & \multirow{2}{*}{ Média } & \multirow{2}{*}{$\mathrm{CV}^{*}(\%)$} \\
\hline & 22 dias & 36 dias & & \\
\hline \multicolumn{5}{|c|}{ Proteína bruta } \\
\hline Tanzânia & $7,86 \pm 0,17$ & $7,42 \pm 0,02$ & $7,64^{\mathrm{a}}$ & \multirow{2}{*}{1,48} \\
\hline Marandu & $7,50 \pm 0,12$ & $7,18 \pm 0,08$ & $7,32^{\mathrm{b}}$ & \\
\hline Média & $7,63^{\mathrm{A}}$ & $7,30^{\mathrm{B}}$ & - & - \\
\hline \multicolumn{5}{|c|}{ Fibra em detergente neutro } \\
\hline Tanzânia & $75,66 \pm 0,27^{\mathrm{Ba}}$ & $77,15 \pm 0,09^{\mathrm{Aa}}$ & 76,40 & \multirow{2}{*}{0,21} \\
\hline Marandu & $72,10 \pm 0,10^{\mathrm{Bb}}$ & $74,04 \pm 0,07^{\mathrm{Ab}}$ & 73,07 & \\
\hline Média & 73,88 & 75,60 & - & - \\
\hline \multicolumn{5}{|c|}{ Fibra em detergente ácido } \\
\hline Tanzânia & $38,12 \pm 0,03^{\mathrm{Bb}}$ & $42,14 \pm 0,01^{\mathrm{Aa}}$ & 40,13 & \multirow{2}{*}{0,32} \\
\hline Marandu & $39,13 \pm 0,10^{\mathrm{Ba}}$ & $40,75 \pm 0,23^{\mathrm{Ab}}$ & 39,94 & \\
\hline Média & 38,62 & 41,44 & - & - \\
\hline \multicolumn{5}{|c|}{ Digestibilidade in vitro da matéria seca } \\
\hline Tanzânia & $54,82 \pm 5,01$ & $48,14 \pm 5,39$ & $51,48^{\mathrm{a}}$ & \multirow{2}{*}{10,01} \\
\hline Marandu & $57,01 \pm 2,35$ & $50,66 \pm 7,17$ & $53,83^{\mathrm{a}}$ & \\
\hline Média & $55,91^{\mathrm{A}}$ & $49,40^{\mathrm{B}}$ & - & - \\
\hline \multicolumn{5}{|c|}{ Digestibilidade in vitro da matéria orgânica } \\
\hline Tanzânia & $50,74 \pm 4,91$ & $43,68 \pm 4,30$ & $47,21^{\mathrm{a}}$ & \multirow{2}{*}{10,95} \\
\hline Marandu & $52,86 \pm 2,73$ & $43,61 \pm 7,68$ & $48,23^{\mathrm{a}}$ & \\
\hline Média & $51,80^{\mathrm{A}}$ & $43,65^{\mathrm{B}}$ & - & - \\
\hline
\end{tabular}

Houve interação entre gramíneas e idades de rebrota para os teores de FDN e FDA. O teor de FDN foi maior no capim-Tanzânia em relação ao capimMarandu nas duas idades de rebrota, e o prolongamento do período de rebrota resultou em elevação no teor de FDN nas duas gramíneas. Chambela Neto et al. (2008) também obtiveram maior teor de FDN no capim-Tanzânia que no capim-Marandu aos 30 dias de rebrota. Para o teor de FDA foi observado que aos 22 dias de rebrota o capim-Marandu apresentou maior teor de FDA do que o capim-Tanzânia, já aos 36 dias de rebrota, a situação se inverteu, o que indica que o capim-Tanzânia depositou 
Rev. Bras. Saúde Prod. Anim., Salvador, v.13, n.1, p.35-46 jan/mar, 2012 http://www.rbspa.ufba.br ISSN 15199940

mais celulose e lignina que o capimMarandu.

Para a DIVMS e DIVMO não foi observada interação significativa entre os fatores capins e idades de rebrota $(\mathrm{P}>0,05)$. Embora tenha ocorrido diferença nos teores de FDN e FDA entre os capins, estas não resultaram em diferenças $(\mathrm{P}>0,05)$ na DIVMS $\mathrm{e}$ DIVMO (Tabela 2), no entanto, o aumento destes constituintes com $\mathrm{o}$ prolongamento do período de rebrota reduziu a DIVMS e DIVMO.

O consumo de matéria seca por ovinos variou entre 2,46 e $2,93 \%$ do peso corporal (Tabela 3). Não houve interação $(\mathrm{P}>0,05)$ entre os fatores para as variáveis consumo de $\mathrm{MS}, \mathrm{PB}$ e NDT, e também não foi observada diferença entre as gramíneas $(\mathrm{P}>0,05)$. Com relação às idades de rebrota observaram-se para ambas as gramíneas, maior consumo de MS, $\mathrm{PB}$ e NDT $(\mathrm{P}<0,05)$ aos 22 dias de rebrota que aos 36 dias de rebrota (Tabela 3 ).

A quantidade de forragem disponível em todos os tratamentos foi maior que os valores considerados limitantes por Roman et al. (2007), que citam para ovinos $1.000 \mathrm{~kg}$ de $\mathrm{MS} / \mathrm{ha}$. A massa de folhas verdes variou de $1.863,50$ a $2.293,14 \mathrm{~kg}$ de $\mathrm{MS} / \mathrm{ha}$, o que também não deve ter limitado o consumo, pois esteve sempre acima de $1.000 \mathrm{~kg}$ de $\mathrm{MS} /$ ha. Embora tenha havido diferença no consumo entre as idades de rebrota, as alturas não diferiram, ou seja, a altura parece não ter sido um elemento determinante do consumo. Esse fato pode ser confirmado uma vez que não houve diferença de consumo entre os dois capins, contudo suas alturas diferiram em cerca de $30 \mathrm{~cm}$.

Tabela 3. Médias e erros-padrão do consumo de matéria seca (\% do PV), PB (g/dia) e NDT (g/dia) por ovinos em pastagens dos capins Tanzânia e Marandu aos 22 e 36 dias de rebrota

\begin{tabular}{|c|c|c|c|c|}
\hline \multirow{2}{*}{ Capim } & \multicolumn{2}{|c|}{ Idade de rebrota } & \multirow{2}{*}{ Média } & \multirow{2}{*}{$\mathrm{CV}^{*}(\%)$} \\
\hline & 22 dias & 36 dias & & \\
\hline \multicolumn{5}{|c|}{ Consumo MS (\% PV) } \\
\hline Tanzânia & $2,87 \pm 0,49$ & $2,26 \pm 0,31$ & $2,53^{\mathrm{a}}$ & \multirow{2}{*}{12,93} \\
\hline Marandu & $2,99 \pm 0,36$ & $2,66 \pm 0,15$ & $2,83^{\mathrm{a}}$ & \\
\hline Média & $2,93^{\mathrm{A}}$ & $2,46^{\mathrm{B}}$ & - & - \\
\hline \multicolumn{5}{|c|}{ Consumo PB (g/dia) } \\
\hline Tanzânia & $74,62 \pm 6,47$ & $56,35 \pm 4,97$ & $65,47^{\mathrm{a}}$ & \multirow{2}{*}{10,44} \\
\hline Marandu & $76,45 \pm 8,16$ & $63,37 \pm 4,97$ & $69,61^{\mathrm{a}}$ & \\
\hline Média & $75,53^{\mathrm{A}}$ & $59,86^{\mathrm{B}}$ & - & - \\
\hline \multicolumn{5}{|c|}{ Consumo NDT (g/dia) } \\
\hline Tanzânia & $437,91 \pm 46,62$ & $355,08 \pm 32,90$ & $396,50^{\mathrm{a}}$ & \multirow{2}{*}{10,55} \\
\hline Marandu & $432,24 \pm 57,12$ & $394,61 \pm 32,13$ & $413,42^{\mathrm{a}}$ & \\
\hline Média & $435,07^{\mathrm{A}}$ & $374,84^{\mathrm{B}}$ & - & - \\
\hline
\end{tabular}

Médias seguidas pela mesma letra minúscula nas colunas e maiúscula nas linhas não diferem entre si pelo Teste Duncan a 5\%.

*Coeficiente de variação. 
A presença de material morto na massa de forragem deve ter contribuído para a redução no consumo pelos ovinos, visto que entre as idades de rebrota $o$ aumento na proporção de material morto foi de $85 \%$ (Tabela 1), o que coincidiu com a redução no consumo (Tabela 3). A maior proporção de material morto no pasto de gramíneas forma uma barreira que impede os animais de aprofundarem o bocado, $\mathrm{o}$ que dificulta a apreensão de forragem, com prejuízos no consumo de $\mathrm{MS}$ (BAUMONT et al., 1998).

O aumento no teor de FDN e FDA, e a redução da DIVMS e DIVMO da forragem provavelmente acentuaram $\mathrm{o}$ efeito de enchimento da foragem no rúmen dos ovinos, o que levou à redução no consumo de MS com o prolongamento do período de rebrota de 22 para 36 dias. Cardoso et al. (2006), obtiveram redução no consumo de MS 3,80 para $3,12 \%$ do PV com o aumento no teor de FDN de 25 para $43 \%$ na dieta de ovinos. A maior proporção de material morto no pasto com 36 dias de rebrota também deve ter contribuído para dificultar a seleção e apreensão de forragem pelos animais, o que levou à redução no consumo de MS.

Ao se tomar por base o consumo de nutrientes estimado nesta pesquisa e ao se considerar as exigências nutricionais de ovinos em terminação nas condições brasileiras descritas por Cabral et al. (2008), aos 22 dias de rebrota, o consumo de NDT permitia ganhos de peso de aproximadamente $73 \mathrm{e}$ $64 \mathrm{~g} /$ dia, e o de PB, ganhos de 85 e $89 \mathrm{~g} /$ dia, respectivamente para os capins Tanzânia e Marandu. Já aos 36 dias de rebrota, o capim-Tanzânia não fornece NDT e PB suficientes sequer para mantença, e o Marandu permitiria ganhos de apenas $20 \mathrm{~g} /$ dia ao considerar a PB e $5 \mathrm{~g} /$ dia, e ao levar em conta o NDT. Ao considerarem-se as exigências nutricionais preconizada pelo NRC (2007), para esses dois nutrientes, as duas gramíneas atenderiam apenas a mantença somente aos 22 dias de rebrota.

Ao avaliarem o desempenho de ovinos em pastagens de capim-Marandu e Tanzânia aos 32 dias de crescimento, Araújo et al. (2008) verificaram que sem suplementação seria possível obter um ganho de peso de aproximadamente $74 \mathrm{~g} /$ dia, próximo do valor estimado neste trabalho, de acordo com as exigências nutricionais descritas por Cabral et al. (2008) para essas gramíneas aos 22 dias de rebrota.

O prolongamento do período de rebrota de 22 para 36 dias leva à redução no consumo de matéria seca, PB e NDT por ovinos em função da queda na qualidade da forragem, tanto do seu valor nutritivo como da estrutura do dossel.

\section{REFERÊNCIAS}

ARAÚJO, D.L.C.; OLIVEIRA, M.E.; ALVES, A.A.; LOPES, J.B.; BERCHIELLI, T.T.; SILVA, D.C. Terminação de ovinos da raça Santa Inês em pastejo rotacionado dos capins Tifton-85, Tanzânia e Marandu, com suplementação. Revista Científica de Produção Animal, v.10, n.2, p.150161, 2008.

BAUMONT, R.; PRACHE, S.; MEURET, M.; MORAND-FEHR, P. How forage characteristics influence behaviour and intake in small ruminants: a review. In: MEETING ON NUTRITION OF SHEEP AND GOATS, 8., 1998, Grignon. Proceedings... Grignon, 1998. p.2-15. 
Rev. Bras. Saúde Prod. Anim., Salvador, v.13, n.1, p.35-46 jan/mar, 2012 http://www.rbspa.ufba.br ISSN 15199940

BARBERO, L.M.; CECATO, U.; LUGÃO, S.M.B; GOMES, J.A.M.; LIMÃO, V.A.; BASSO, K.C. Produção de forragem e componentes morfológicos em pastagem de coastcross consorciada com amendoim forrageiro. Revista Brasileira

Zootecnia, v.38, n.5, p.788-795, 2009

BERCHIELLI, T.T.; OLIVEIRA, S.G.; CARRILHO, V.M.; FEITOSA, J.V.;

LOPES, A.D. Comparação de marcadores para estimativas de produção fecal e de fluxo de digesta em bovines Revista Científica de Produção Animal, v.34, n.3, p.987996, 2005.

BOUCHENAK-KHELLADI, Y.; VERBOOM, G.A.; HODKI NSON, T.R.; SALAMIN, N.; FRANCOIS, O; CHONGHAILE, G.N.; SAVOLAINEN, $\mathrm{V}$. The origins and diversification of $\mathrm{C} 4$ grasses and savannaa dapted ungulates Global Change Biology, v.15, p.23972417, 2009.

BRÂNCIO, P.A.; EUCLIDES, V.P.B.; NASCIMENTO JÚNIOR, D.; FONSECA, D.M.; ALMEIDA, R.G.; MACEDO, M.C.M.; BARBOSA, R.A. Avaliação de três cultivares de Panicum maximum Jacq. sob pastejo:

disponibilidade de forragem, altura do resíduo pós-pastejo e participação de folhas, colmos e material morto Revista Brasileira Zootecnia, v.32, n.1, p.5563, 2003.

CABRAL, L.S.; NEVES, E.M.O.; ZERVOUSDAKIS, J.T.; ABREU, J.G.; RODRIGUES, R.; SOUZA, A.L.; OLIVEIRA, I.S. Estimativa dos requisitos nutricionais de ovinos em condições brasileiras. Revista

Brasileira de Saúde e Produção Animal [Online], v.6, n.3, p.529-542, 2008.
CARDOSO, A.R.; PRES, C.C.; CARVALHO, S.; GALVANI, D.B.; JOCHIMS, F.; HASTENPFLUG, M; WOMMER, T.P. Consumo de nutrientes e desempenho de cordeiros alimentados com dietas que contêm diferentes níveis de fibra em detergente neutro. Ciência Rural, v.36, n.1, p.215-221, 2006.

CAPPELLE, E.R.; VALADARES FILHO, S.C.; SILVA, J.F.C.; CECON, P.R. Estimativas do valor energético a partir de características químicas e bromatológicas dos alimentos. Revista Brasileira Zootecnia, v.30, n.6, p.1837-1856, 2001.

CÂNDIDO, M.J.D.; SILVA, R.G.; NEIVA, J.N.M.; FACÓ, O.; BENEVIDES, Y.I.; FARIAS, S.F. Fluxo de biomassa em capimTanzânia pastejado por ovinos sob três períodos de descanso. Revista Brasileira Zootecnia, v.35, n.6, p.2234-2242, 2006.

CÂNDIDO, M.J.D.; ALEXANDRINO, E; GOMIDE, C.A.M.; GOMIDE, J.A.; PEREIRA, W.E. Período de descanso, valor nutritivo e desempenho animal em pastagem de Panicum maximum cv. Mombaça sob lotação intermitente Revista Brasileira de Zootecnia, v.34, n.5, p.1459-1467, 2005

CARVALHO, P.C.F.; KOZLOSKI, G.V.; RIBEIRO FILHO, H.M.N.; REFFATTI, M.V.; GENRO, T.C.M. EUCLIDES, V.P.B. Avanços metodológicos para determinação do consumo de ruminantes em pastejo.

Revista Brasileira de Zootecnia, v.36, p.151 - 170, 2007. Supl. 
Rev. Bras. Saúde Prod. Anim., Salvador, v.13, n.1, p.35-46 jan/mar, 2012 http://www.rbspa.ufba.br ISSN 15199940

CECATO, U.; CASTRO, C.R.C.; CANTO, M.W.; PETERNELLI, M.; ALMEIDA JÚNIOR, J.; JOBIM, C.C.; CANO, C.C.P. Perdas de forragem em capim-Tanzânia (Panicum maximum Jacq cv. Tanzania-1) manejado sob diferentes alturas sob pastejo Revista

Brasileira de Zootecnia, v.30, n.2, p.294-301, 2001.

CHAMBELA NETO, A.; FERNANDES, A.M.; DERESZ, F.; VIEIRA, R.A.M.; FONTES, C.A.A.; DEMINICIS, B.B.; BONAPARTE, T.P. Composição químico-bromatológica e digestibilidade de três gramíneas tropicais em Minas Gerais. Arquivos de Zootecnia, v.57, n.219, p.357-360, 2008.

DETMANN, E.; PAULINO, M.F.; ZERVOUDAKIS, J.T. Cromo e indicadores internos na determinação do consumo de novilhos mestiços, suplementados, a pasto Revista

Brasileira de Zootecnia, v.30, n.5, p.1600-1609, 2001.

EUCLIDES, V.P.B.; COSTA, F.P.; MACEDO, M.C.M.; FLORES, R.; OLIVEIRA, M.P. Eficiência biológica e econômica de pasto de capim-Tanzânia adubado com nitrogênio no final do verão. Pesquisa Agropecuária Brasileira, v.42, n.9, p.1345-1355, 2007.

FAGUNDES, J.L.; FONSECA, D.M.; MISTURA, C.; MORAIS, R.V.; VITOR, C.M.T.; GOMIDE, J.A.; NASCIMENTO JÚNIOR, D.; COSTA, L.T. Características morfogênicas e estruturais do capim-braquiária em pastagem adubada com nitrogênio avaliadas nas quatro estações do ano.

Revista Brasileira de Zootecnia, v.35, n.1, p.21-29, 2006.
JANUSCKIEWICZ, E.R.; MAGALHÃES, M.A.; RUGGIERI, A.C.; REIS, R.A. Massa de forragem, composição morfológica e química do capim-Tanzânia sob diferentes dias de descanso e resíduos pós-pastejo. Bio Science, v.26, n.2, p.161-172, 2010.

NATIONAL RESEARCH COUNCIL NRC. Nutrient Requirements of Small Ruminants: sheep, goats, cervids, and new world camelids. Washington: National Academic Press, 2007.

OLIVEIRA, M.E.; NASCIMENTO, M.P.S.C.B.; TEIXEIRA, G.; LOPES, J.B.; VELOSO FILHO, E.S.; SÁ JÚNIOR, R.P.; RODRIGUES, J.P.; FERRAZ, M.S. Produção de matéria seca e qualidade de três gramíneas forrageiras e desempenho produtivo de ovinos sob pastejo rotacionado. Revista Científica de Produção Animal, v.7, n.2, p.35-44, 2005.

PACIULLO, D.S.C.; GOMIDE, J.A.; QUEIROZ, D.S. Composição química e digestibilidade in vitro de lâminas foliares e colmos de gramíneas forrageiras, em função do nível de inserção no perfilho, da idade e da estação de crescimento. Revista Brasileira de Zootecnia, v.30, n.3, p.964-974, 2001. Supl. 1.

ROMAN, J.; ROCHA, M.G.; PIRES, C.C.; ELEJALDE, D.A.G.; KLOSS, M.G.; OLIVEIRA NETO, R.A. Comportamento ingestivo e desempenho de ovinos em pastagem de azevém (Lolium multiforum Lam) com diferentes massas de forragem. Revista Brasileira Zootecnia, v.36, n.4, p. 780788, 2007. 
Rev. Bras. Saúde Prod. Anim., Salvador, v.13, n.1, p.35-46 jan/mar, 2012 http://www.rbspa.ufba.br ISSN 15199940

SANTELLO, G.A.; MACEDO, F.A.F.; MEXIA, A.A.; SAKAGUTI, E.S.;

DIAS, F.J.; PEREIRA, M.F.

Características de carcaça e análise do custo de sistemas de produção de cordeiras $1 / 2$ Dorset Santa Inês. Revista Brasileira de Zootecnia, v.35, n.4, p.1852-1859, 2006.

SAS INSTITUTE. SAS/STAT. User's guide. Versão 9.1.3. Cary, 2004.

SILVA, D.C.; QUEIROZ, A.C. Análise de alimentos: métodos químicos e biológicos. 3.ed. Viçosa: Universidade Federal de Viçosa, 2002, 235p.

SOUZA, G.B.; NOUEIRA, A.R.A.; SUM, L.M.G; BATISTA, L.A.R.

Método alternativo para determinação de fibra em detergente neutro ácido. São Carlos. EMBRAPA Pecuária Sudeste, 1999. 21p. (Boletim de Pesquisa, 4).
SUN, X.Z.; WAGHORN, G.C;

CLARK, H. Cultivar and age of regrowth effects on physical, chemical and in sacco degradation kinetics of vegetative perennial ryegrass (Lolium perenne L.). Animal Feed Science and Technology, v.155, p.172-185, 2010.

TAMASSIA, L.F.M.; HADDAD, C.M.; CASTRO, F.G.F.; VENDRAMINI, J.M.B; DOMINGUES, J.L. Produção e morfologia do capim de Rhodes em seis maturidades. Scientia Agricola, v.58, n.3, p.599-605, 2001.

TILLEY, J.M.A.; TERRY, R.A. A twostage technique for the in vitro digestion of forage crops. Journal British

Grassland Society, v.18, n.2, p.104111, 1963.

Data de recebimento: 01/05/2011

Data de aprovação: 02/12/2011 